weaker in the light of the night sky. A discovery of this significance for the physics of the upper atmosphere must be carefully considered, and a programme of exhaustive investigation of the 3470 line is now under way. Until further study, therefore, the identification must be given as a tentative one, attractive as the above arguments may sound.

Departments of Astronomy and Physics, JOSEPH KAPLAN.

University of Califormia, Los Angeles.

${ }^{1}$ Kaplan, Phys. Rev., 48, 800 (1935).

' Dufay, J. Phys., vii, 5, 523 (1934).

"Gauzit, J. Phys., vii, 5, 527 (1934).

\section{Effect of Catastrophic Ionospheric Disturbances on Low-Frequency Radio Waves}

K. G. Budden and J. A. Ratcliffe ${ }^{1}$ have described an effect of catastrophic ionospheric disturbances on low-frequency radio waves $(16 \mathrm{kc} . / \mathrm{s}$.$) , but this action$ did not show an increase in atmospherics.

This last statement agrees with our observations. It is certain that an increase in atmospherics seldom appears on a frequency of $12 \mathrm{kc}$./s. This has been known for several years. A recent observation shows that, on a frequency of $17 \mathrm{kc} . / \mathrm{s}$., increase had already disappeared.
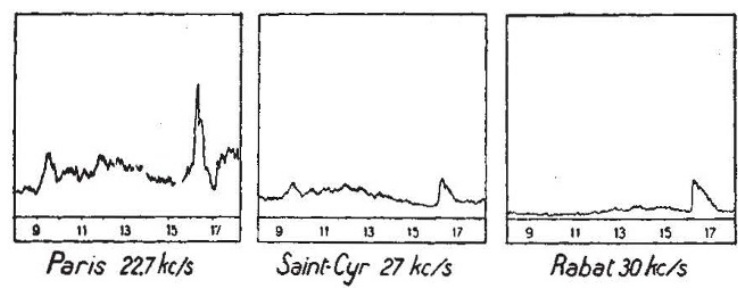

Increases noticed at Paris (22 kc./s.), St. Cyx (27 kc./s.) and Rabat (30 kc./s.) on November 6, 1936 (date of the anomally published by $\mathrm{K}$. G. Budden and J. A. Ratcliffe), are shown on the accompanying figure.

\section{Office National Météorologique, \\ 196 rue de l'Université, \\ Paris, VIIe. \\ Feb. 19. \\ ${ }^{1}$ NATURE, 140, 1060-1061 (1937).}

\section{R. Bureau.}

\section{Vitamin E: Structure of $\beta$-Tocopherol}

IN a recent publication ${ }^{1}$ we indicated that $\beta$-tocopherol, $\mathrm{C}_{28} \mathrm{H}_{48} \mathrm{O}_{2}$, might be a coumaran or chroman derivative bearing a long side chain in the heterocyclic nucleus.

With the view of testing this hypothesis, we have synthesized 5-hydroxy-2:4: 6 : 7-tetramethylcoumaran (I), m.p. 124-125 ${ }^{\circ}$, starting from pseudocumoquinol and allyl bromide, and also 5-hydroxy4 : 6 : 7-trimethyl-2-n-heptadecylcoumaran (II), m.p. 95-95.5 $5^{\circ}$, isomeric with $\beta$-tocopherol, from pseudocumoquinone and ethylsodiostearoylacetate followed by partial hydrogenation of the intermediate coumarone.<smiles></smiles>

$$
\begin{aligned}
\text { I } \mathrm{R} & =\mathrm{CH}_{3} \\
\text { II } \mathrm{R} & =\mathrm{C}_{17} \mathrm{H}_{35}
\end{aligned}
$$

Both the synthetic coumarans are very similar to $\beta$-tocopherol in absorption spectrum and reducing properties.

\begin{tabular}{|cc|c|c|c|c|c|}
\hline \multicolumn{2}{|c|}{ Substance } & & \multicolumn{2}{c|}{ Wave-length } & \multicolumn{2}{c|}{$\varepsilon$ mol. } \\
\cline { 3 - 5 } & & & Max. & Min. & Max. & Min. \\
\hline$\beta$-tocopherol &.. &.. & $295 \mathrm{~m} \mu$ & $260 \mathrm{~m} \mu$ & 3577 & 520 \\
\hline 'Heptadecylcoumaran' &.. & $297 \mathrm{~m} \mu$ & $258 \mathrm{~m} \mu$ & 3993 & 624 \\
\hline 'Methylcoumaran' &.. & $296 \mathrm{~m} \mu$ & $270 \mathrm{~m} \mu$ & 3840 & 1305 \\
\hline
\end{tabular}

When thermal decomposition is attempted, synthetic 5-hydroxy-4:6:7-trimethyl-2-n-heptadecylcoumaran distils at $370^{\circ}$ without charring, giving a mixture from which a trace of a quinol is obtained, m.p. 185-190 (subl.) (cf. thermal decomposition of tocopherols, loc. cit.).

These results together with the surface film measurements of Dr. Danielli, recorded below, give support to the view that $\beta$-tocopherol is a coumaran derivative. The detailed configuration of the side chain, and the distribution of $\mathrm{CH}_{3}$-groups in the ring system remain to be determined. Side methyl estimations of $\beta$-tocopherol indicate the presence of six or seven $\mathrm{CH}_{3}(\mathrm{C})$. Two or possibly three of these can be attached to the aromatic nucleus; the remaining three to five can be accounted for by formulating the side chain and the heterocyclic nucleus as a 'dihydrophytyl'-like structure; such a structure would explain also the oily nature of the vitamin and the ready production of quinols on thermal decomposition. This hypothesis is supported by results of oxidation : two oily fatty acids, $\mathrm{C}_{17-18}$ and $\mathrm{C}_{11-12}$, are obtained, giving crystalline phenylphenacylesters.

F. Bergel.

A. $\boldsymbol{J}_{\text {ACOB. }}$

A. R. ToDn.

T. S. Work.

Biochemical Department, Lister Institute, London. March 10.

${ }^{2}$ Bergel, Todd and Work, J. Chem. Soc., 253 (1938).

Both $\beta$-tocopherol allophanate and 5-hydroxy$4: 6$ : 7-trimethyl-2- $n$-heptadecylcoumarone spread on $N / 100$ hydrochloric acid to give stable films. The limiting area of the first compound is $30 \mathrm{sq}$. A. and that of the coumarone is 26 sq. A. $p$-Hexadecylcyclohexanol has a limiting area of $30 \mathrm{sq}$. A. and the lactone of $\gamma$-hydroxystearic acid an area of 29 sq. A. It may therefore be concluded that the first two compounds mentioned are analogous in structure and that in cross-section $\beta$-tocopherol cannot have a ring system more than one ring in thickness measured perpendicular to the side chain. The ring system cannot be analogous to a phenanthrene or sterol skeleton.

\section{J. F. DANIELLI.}

Department of Biochemistry, University College, London. 